\title{
THE ATTIYUDES OF MODERN LANGUAGE TEACHERS TOWARD INSTRUCTIONAL MEDIA
}

\author{
by Wm. Flint Smith and Frank J. Woerdehoff
}

\section{INTRODUCTION}

Over a decade has passed since Title III of the National Defense Education Act provided matching monies for the purchase of equipment to improve instruction in modern foreign languages. Since 1958 literally tens of hundreds of electro-mechanical devices have been installed in secondary schools and colleges in the United States. After ten years of experience educators generally agree that the language laboratory and its variations, such as the electronic classroom, have emerged as an important characteristic of the rew look in language training (Hayes, Lambert, and Tucker, 1967).

\section{BACKGROUND}

Attempts to evaluate the relative effectiveness of the language laboratory have proven largely inconclusive or contradictory at all levels of instruction (Carroll, 1963, 1965; Keating, 1963; Lorge, 1964; Smith, 1968a, 1968b) despite improvements in equipment, instructional materials - both taped and textbook - and in standardized measures of achievement (see for example Pimsleur, 1967).

Successful use of the language laboratory is predicated on various general assumptions: 1) that the facilities are used on a scheduled and systematic basis (Hutchirson, 1966); 2) that the equipment is wellmaintained (Hayes, 1969) and capable of reproducing fundamental phonemic contrasts (Locke, 1965); 3) that the student's language efforts are systematically monitored and evaluated (Bauer, 1964); 4) that the students are prepared for their laboratory experience prior to working with language tapes (Hocking. 1967); and 5) that there is a high correlation between the behaviors that are fostered in the laboratory and those that are measured in weekly or end-of-term examinations (Stack, 1966).

\section{STUDENT FACTORS}

Several student factors contribute to the relative impact of tapeguided practice on learning a second language. Carroll (1963) defined language aptitude as an inverse function of the time the learner takes to acquire a criterion mastery in the task to be learned. Pimsleur and others (1962) further established the degree of contribution of 
intelligence and motivation. Lambert (1963) delineated the role of attitude toward ethnic groups in bicultural and monocultural settings in learning a second language.

Smith and Hocking (1969b) assessed student's attitudes toward media and reported that high school students in three languages expected tape-guided practice to be good, helpful, rewarding, meaningful, and valuable. The student's rating after nine months of instruction had changed hardly at all. Average correlations between attitude scores and several interim and end-of-term achievement scores, however, proved non-significant. Apparently, the attitudes of these students were not strong enough to influence how well they performed on tests.

\section{TEACHER FACTORS}

Beyond the student's interest-motivation or attitude-orientation, two additional factors can contribute to the successful use of electromechanical devices in language learning: 1) the teacher's skill in making use of laboratory materials and facilities, and 2) the teacher's attitude toward language practice tapes, the language laboratory, and related equipment. "Sound labsmanship" is virtually unquantifiable, and although Lorge (1964) reported that student's attitudes toward the language laboratory reflect the ease with which teachers handle the equipment, and Carroll (1966) further noted the importance of the amount of time the individual is able to spend practicing with recorded materials, Bumpass (1963), and more recently Smith and Hocking (1969a), have reported that teachers often do not use laboratory or classroom equipment often enough or in long-enough periods for the learner to achieve a meaningful degree of concentration.

\section{THE PROBLEM}

The effectiveness of the teacher's use of media in second-language teaching might be reflected in their attitudes toward the entire language-laboratory concept. The following questions are therefore relevant: What are representative teacher attitudes toward languagelaboratory equipment and materials? What changes in attitudes will accrue as teachers use these media?

Some recent answers to these questions are the by-product of a two-year investigation designed primarily to assess the relative advantages of three kinds of equipment: 1) the "chandelier-type" electronic classroom; 2) the audio-active language laboratory; 3) the recordplayback laboratory. The primary conclusions of the study have been reported elsewhere (W. F. Smith, 1969). The attitudes of the teachers were also investigated and are reported here for the first time. 


\section{THE INVESTIGATION}

The beginning language classes and their teachers of a large comprehensive high school formed the respective treatment conditions and experimental population under consideration. One teacher each of French and Spanish and two in German taught at least three classes, one of them meeting in a conventional classroom but with two or three half-period migrations per week to either a broadcast or $a$ record-playback laboratory; another of his classes met in an electronic classroom. Finally, in each language. there was a control group that used no tapes or equipment. In the classes that used the laboratories, tape-guided practice was necessarily concentrated in half-period sessions; in the electronic-classroom treatment condition, an equal amount of such practice could be distributed throughout the week as the teacher desired: within each language the fundamental objectives, instructional materials, and criterion measures were identical. The dependent variable therefore consisted of variation in the use of the three respective equipment configurations in the various groups in each language.

\section{TEACHER ATTITUDE}

An estimation of teacher attitude toward instructional media was obtained under the format of the semantic differential (Osgood, 1957). Twenty-one pairs of sharply contrasting adjectives of an evaluative or affective nature were selected. These twenty-one pairs of adjectives, e.g., good-bad, valuable-worthless, were then separated by rating scales numbered 7 (most favorable) through 1 (least favorable). The direction of the polarity of the scales was randomized as a precaution against response bias. Finally three concepts "Language Practice Tapes," "Language Laboratory," and "Electronic Classroom" were rated by each teacher at the beginning and again at the end of the school year.

To check upon the external validity of the attitude instrument and on the representativeness of the experimental teachers' affective orientation, an identical instrument was administered to a reference group of nineteen additional high-school language teachers of similar experience, age, and assignment. The average ratings of the respective concepts by the two teacher groups are presented, by scale, in Figure 1 where each profile delineates an overall attitude orientation for the combined groups.

A positive orientation toward media for language learning is clearly evident. The teachers uniformly judged language practice tapes to be good, helpful, clear, meaningful, and valuable. As a whole, the equipment for machine-guided practice also received favorable appraisal. When the ratings for the electronic classroom and the lan- 
Scales

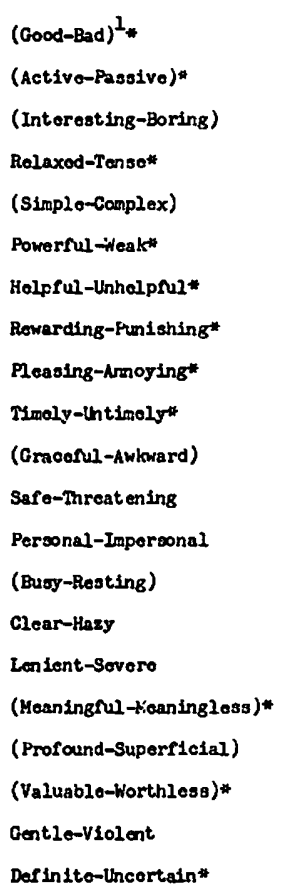

(7) (6) (5) (4) (3) (2) (1)

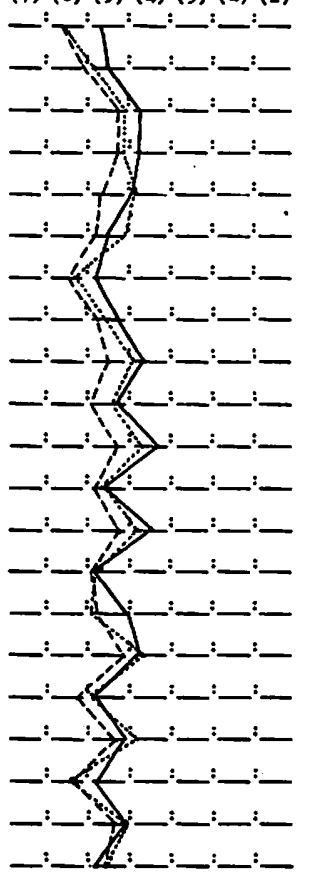

P1gure 1. Preliminary Ratings of Teachor Groups ( $\mathrm{N}=23$ ).

1 seales onclosed in parentheses were originally presented with reversed polarity.

*Rstimatea attitude.

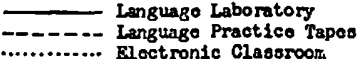

guage laboratory were compared however, the combined groups indicated a significant preference for the in-class facilities over the conventional laboratory (p. 01; Signed-Ranks test).

The semantic differential technique enables one to compare differences in attitude between groups, and differences across time. Hence, two additional analyses were performed: 1) the differences in attitude between the experimental and reference group teachers were compared and 2) the changes in the experimental teacher attitudes after nine months were assessed. 
Prior to comparing attitudes between the teacher-groups, factor analysis was used to define those scales (starred items in the Figures) which were the most evaluative for each concept." An "attitude toward media" score for each teacher was found by summirg across his responses to the appropriate "evaluative" scales defined through factor analysis. ${ }^{2}$

\section{EXPERIMENTAL VERSUS REFERENCE-GROUP ATTITUDES}

Differences between the experimental and reference group teachers were evaluated by means of a t-test for correlated samples. 3 The average attitude scores for both groups are listed on Table 1 . The experimental group tended to rate the electronic classroom more favorably (p. 01) than did the reference-group teachers; correspondingly, they rated the language laboratory lower, although not significantly so. Both groups were practically equal in their evaluation of language practice tapes.

$$
\text { Tablo } 1
$$

Mean Attitude Scores for the Coicepts Language Laboratory, Electronic Classroor,, and Languape Practice Tapes Coapared Botween Teacher Fiof erenco Group and Experimental Group

Concept Rated

Lenguage Laboratory

Electronic Classroor:

Languape Practice Tapes

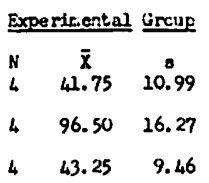

Reference Group

\begin{tabular}{|c|c|c|c|c|}
\hline $\begin{array}{l}N \\
19\end{array}$ & $\begin{array}{c}\overline{\bar{X}} \\
50.29\end{array}$ & 8.81 & $\begin{array}{l}\mathrm{df} \\
4\end{array}$ & $\begin{array}{c}t^{\prime} \\
-1.66\end{array}$ \\
\hline 19 & 86.41 & 10.70 & 4 & 5.29 \\
\hline 19 & 41.65 & 6.96 & 4 & .51 \\
\hline
\end{tabular}

The results of the analyses between groups tend to enhance the validity of the measurement instrument and the sample of teachers surveyed since the comparisons revealed a high degree of congruence in attitudes toward media. The significantly higher evaluation of the electronic classroom by the experimental-group teachers is not incompatible with this conclusion; it simply reflects an initial Hawthorne effect that can be expected in any experimental setting where the new (e.g., electronic classroom) is compared with the traditional (e.g., language laboratory).

IPrincipal components solution (Harman, 1967). Rotation of the respective matrices was terminated after extraction of the sixth orthogonal factor for the concepts "Language Laboratory" and "Language Practice Tapes." The principal components solution, unrotated, was accepted for the concept "Electronics Classroom." All calculations were performed on the Purdue IBM 7090 and CDC 6500 computers.

2For Language Laboratory: interesting, definite, helpful, profound, valuable, timely, safe, powerful, active, rewarding, and good.

For Language Practice Tapes: helpful, good, meaningful, valuable, rewarding, interesting, timely, and personal.

For Electronic Classtoom: summed over all scales.

3The degrees freedom adjusted for the smallness of the samples were taken as equal to four in all comparisons. 


\section{Instructional Media}

\section{STABILITY OF TEACHER ATTTTUDES}

The stability of the experimental-teacher attitudes was assessed by comparing their pre-and post-experiment profiles. No significant shift in attitude was evident for the Spanish and German teachers. ${ }^{4}$ A significant shift was noted for the French teacher, however, and would seem to indicate a growing dissatisfaction with the respective media as the academic year progressed.

A similar trend can be seen in the respective pre-post attitude profiles averaged across all four teachers (Figures 2, 3, 4). Truly significant differences may be masked by the effects of regression; nevertheless, the post-profile ratings as evaluated by the Signed-Ranks test were significantly smaller for the concepts "Language Labora-

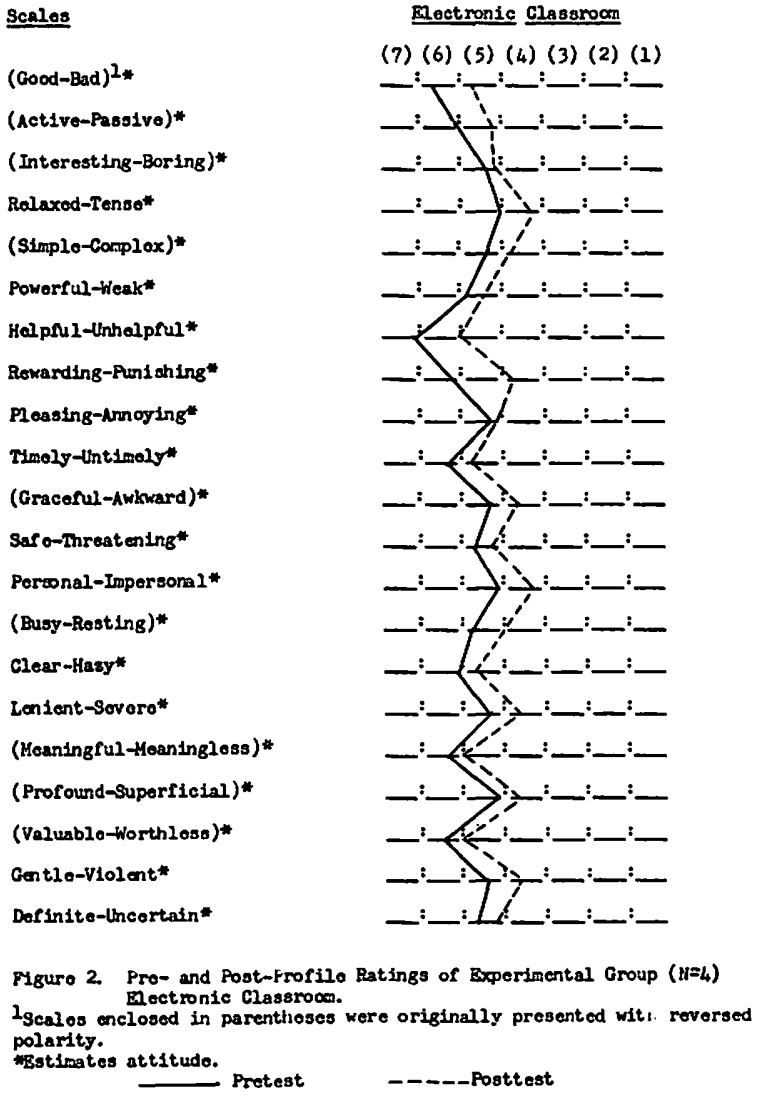

For the individual, a difference in two scale units under test-re-test conditions constitutes evidence of a significant change at the .05 level of confidence (Osgood, 1957). 
Scales

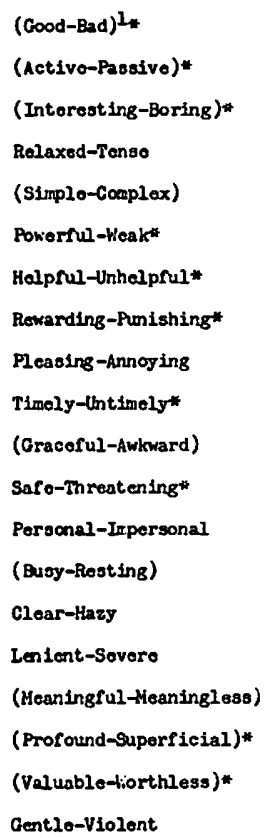

Desinite-Uncertain*
Language Laboratory

(7) (6) (5) (4) (3) (2) (1)

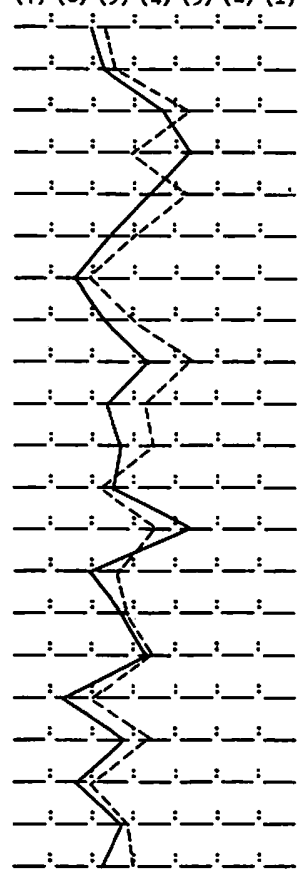

Figuro 3. Pro- and Post-Profile Ratings of Exporimental Oroup (N=4)

Language Laboratory.

Iscales enclosed in parenthoses noro origirally presented with reversed polarity.

inatimates attitude.

tory" (p. 05), and for "Electronic Classroom" (p. 01) but not for "Language Practice Tapes." These results give further evidence that the Hawthorne effect had disappeared after nine months of instruction. Moreover, its overall effect on the use of the equipment was apparently minimal, for although the teachers expressed a greater preference for the electronic classroom equipment, they actually used it least of all. The language laboratory, rated lower initially, not only enjoyed greater uses but apparently contributed more to achievement than did the electronic classroom (Smith,' 1969).

sTotal minutes use of equipment during nine months instruction, by languages: French: Electronic Classroom (EC), 1300; Audio-active Laboratory (AAL), 1425; Record-playback Laboratory (RPL); 1465. German: EC-1, 1328; EC-2, 1415; AAL, 1350; RPL; 1545. Spanish: EC, 1817; RPL, 1937. 
Scales

(Good-Bad $)^{1}$ *

(Activo-Passivo)

(Intaresting-Boring)*

Rolexed-Tanse

(Simple-Complex)

Powerrul-Woak

Helprul-Unholpful*

Rowarding-Punishing*

Ploasing-Annoying

Timely-intinely

(Graceful-Akkward)

Safo-Threatening

Porsonal-Ifoporsonal*

(Busy-Roating)

Clear-Hazy

Len1ent-Sovero

(Keaningrul-Hoaningless)*

(Profound-Suporficial)

(Valuable-itorthless)*

Gentle-Violent

Definito-uncertain
Lenguage Practice Tapes
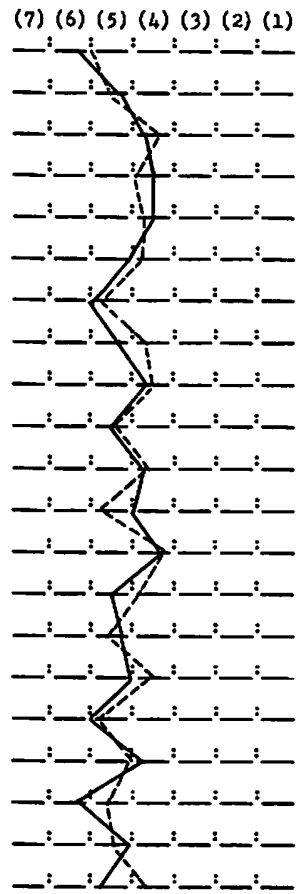

Figuro 4. Pro- and Post-Profile Ratings of Exporimental Group ( $N=4$ ) Lenguage Practice Tapos.

Iscales enclosed in parentheses wore originally prosented with roversod polarity.

igstimatos attitude.

Protest

---- Posttast

\section{CONCLUSION}

Two conclusions may be drawn from the results of this small scale study. The first and most interesting is that the high school language teachers did not reflect strongly positive or negative attitudes toward the media they used in their classes. Their ratings were somewhat positive to be sure; however, this may have reflected a modest degree of expectancy rather than firm attitudes based upon a solid background of successful experience.

Second, within the small sample of experimental teachers, attitude toward-media was not related to their use of the equipment or the tapes. The novelty of in-class equipment disappeared for, in the final 
analysis, the laboratory groups received more total minutes of machine-guided practice than their classroom counterparts.

Finally, although the effects of attitude toward media were found to be negligible in this study, one must conclude that teacher attitudes still remain as potential contributing factors to error variance in educational research. No matter what variables between treatment conditions one measures it is important to be able to estimate the effects of attitude where human factors are involved. The semantic differential is an easily constructed device and a valid technique for the investigator who wants to define the limits and assess the degree of teacher attitude in his respective experimental setting.

\section{BIBLIOGRAPHY}

Bauer, Eric W. " $\dot{A}$ Study of the Effectiveness of Two Language Laboratory Conditions on the Teaching of Second-year German." International Review of Applied Linguistics 2 99-112; 1964.

Bumpass, Donald E. An Appraisal of Language Laboratories in Public Schools in the United States. (Unpublished Ph.D. Dissertation) Texas Technological College, 1963.

Carroll, John B. "Research on the Teaching of Foreign Languages." Handbook of Research on Teaching. N. L. Gage, editor. New York: Rand McNally C., 1963.

Carroll, John B. "Research on Foreign Language Teaching: The last Five Years." Reports of the Working Committees: Northeast Conference on the Teaching of Foreign Languages. R. G. Mead, editor. Mensha, Wisconsin: The George Banta Co., Inc., 1966.

Guilford, J. P. Fundamental Statistics in Psychology and Education. (Fourth Edition) New York: McGraw-Hill Book Co., 1965.

Harman, H. H. Modern Factor Analysis (Second Edition) Chicago: University of Chicago Press, 1967.

Hayes, Alfred S., W. E. Lambert, and R. G. Tucker. "Evaluation of Foreign Language Teaching" Foreign Language Annals 1 22-44; 1967.

Hayes, Alfred S. Language Laboratory Facilities: A Technical Guide for the Selection, Purchase, Use, and Maintenance (Second Edition). London: Oxford University Press, 1968.

Hocking, Elton. Language Laboratory and Language Learning, Monograph II (Second Edition). Washington, D. C.: Department of Audiovisual Instruction of the National Education Association, 1967. 
Hutchinson, Joseph C. "The Language Laboratory: Equipment and Utilization." Trends in Language Teaching. A. Valdman, editor. New York: McGraw-Hill Book Co., 1966.

Keating, Raymond F. A Study of the Effectiver:ess of Language Laboratories: A Preliminary Evaluation in Twenty-one School Systems of the Metropolitan School Study Council. New York: Institute of Administrative Research, Teachers College, Columbia University, 1963.

Lambert, Wallace E. "Psychological Approaches to the Study of Languages, Part II: On Second Language Learning and Bilingualism." Modern Language Journal 47(3) 114-21; 1963.

Locke, William N. "The Future of Language Laboratories" Modern Language Journal 40(5) 294-304; 1965.

Lorge, Sarah W. "Language Laboratory Research Studies in New York High Schools: A Discussion of the Program and Findings." Modern Language Journal 48(7) 409-19; 1964.

Osgood, Charles, E., G. J. Suci, and P. H. Tennenbaum. The Measurement of Meaning. Chicago: University of Press, 1957.

Pimsleur, Paul, L. Mosberg and A. V. Morrison. "Student Factors in Foreign Language Learning: A Review of the Literature." Modern Language Journal 46(4) 160-70; 1962.

Smith, Phillip D., Jr., and Emanual Berger. An Assessment of Three Foreign Language Strategies Utilizing Three Language Laboratory Systems. Project No. 5-0683 (OE-7-48-9013-272). Washington, D. C.: U. S. Department of Health, Education, and Welfare, 1968a.

Smith, Phillip D., Jr., and Helmut A. Baranyi. A Comparative Study of the Effectiveness of the Traditional and Audiolingual Approaches to Foreign Language Instruction Utilizing Laboratory Equipment: Final Report, Project No. 7-0133; OE-7-070133-0445. Washington, D. C.: U. S. Department of Health, Education, and Welfare, 1968b.

Smith, W. Flint. The Language Laboratory and the Electronic Classroom: A Comparison of their Relative Contribution to Achievement in Three Languages in the Comprehensive High School (Unpublished Ph.D. Dissertation) Purdue University, 1969.

Smith, W. Flint and Elton Hocking. "The Student's Attitude." Newsletter of the Foreign Language Association of Northern California $17(68): 7-8,3 ; 1969$ a. 
Smith, W. Flint and Elton Hocking. "The Fallacy of Accessibility:" Newsletter of the National Association of Language Laboratory Directors 3(3):10-13; 1969b.

Stack, Edward M. Language Laboratory and Modern Language Teaching. (Revised Edition.) New York: Oxford Press, 1966.

Table 1

Mean Attitude Scores for the Concepts Language Laboratory, Electronic Classroom, and Language Practice Tapes Compared Between Teacher Reference Group and Experimental Group

Figure 1. Preliminary Ratings of Teacher Groups $(\mathrm{N}=23)$.

iscales enclosed in parentheses were originally presented with reversed polarity.

Estimates attitude.

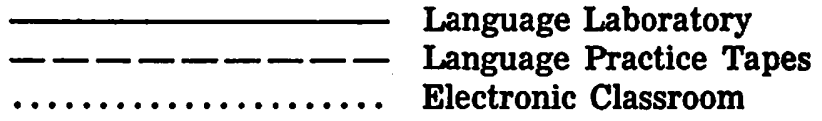

Figure 2. Pre- and Post-Profile Ratings of Experimental Group $(\mathrm{N}=4)$ Electronic Classroom.

iScales enclosed in parentheses were originally presented with reversed polarity.

Estimates attitude.

Figure 3. Pre- and Post-Profile Ratings of Experimental Group ( $N=4)$ Language Laboratory.

iScales enclosed in parentheses were originally presented with reversed polarity.

*Estimates attitude.

\section{Pretest} - - - - Posttest

Figure 4. Pre- and Post-Profile Ratings of Experimental Group ( $N=4)$ Language Practice Tapes.

iScales enclosed in parentheses were originally presented with reversed polarity.

Estimates attitude.

ABOUT THE AUTHORS: Dr. Frank Woerdehoff is the Associate Dean of Education in Charge of Teacher Certification at Purdue. Prof. William Flint Smith is Director of Language Laboratories and professor of Spanish at Purdue. 